\title{
DESCRIPTION OF FIVE DEEP CARIES MANAGEMENT METHODS AND THEIR USE IN CONTEMPORARY DENTISTRY
}

\author{
Anna Jodłowska', Alicja Leś-Smolarczyk ${ }^{2}$, Lidia Postek-Stefańska' \\ 'Department of Pediatric Dentistry, Medical University of Silesia, Katowice, Poland \\ ${ }^{2}$ Academic Centre of Dentistry, Bytom, Poland
}

\begin{abstract}
Deep caries treatment is associated with the loss of hard dental tissue and pain during debridement of the cavity and is very time-consuming. Traditional management (complete caries removal) is associated with high complication rates. In order to reduce the number of problems, other methods can be used such as stepwise excavation, partial caries removal and cavity restoration during the same visit, and no dentinal caries removal. The aim of this paper is to compare the efficacy of five deep caries treatment methods based on the literature. It describes complete caries removal, indirect pulp treatment, stepwise excavation, 1-visit partial caries removal and no dentinal caries removal. The work focuses on methods which are minimally invasive in relation to hard dental tissues and ensure maximum protection of vital dental tissue. The present study suggests the need to limit complete cavity preparation in the treatment of deep caries, especially at the developmental age. Such an approach decreases the risk of pulp exposure and substantial loss of hard dental tissue to improve the conditions of secondary dentin formation.
\end{abstract}

KEY wORDS: deep caries, stepwise excavation, partial caries removal, atraumatic restorative treatment.

J Stoma 2018; 71, 3: 302-307

DOI: https://doi.org/10.5114/jos.2018.80639

\section{INTRODUCTION}

Dental caries is one of the most common diseases in the world. Its treatment is associated with the loss of dental tissue, pain and dental anxiety [1,2]. Despite the possibility to use various treatment methods, most dentists choose traditional management which involves complete removal of carious dentine and cavity restoration. This method is associated with a high rate of complications involving pulp exposure, particularly during the developmental age, due to the structure of the teeth in this period. The pulp chamber is large and the dentinal tubules are wide in diameter, which causes rapid caries progression. In order to reduce the number of complications and pain, as well as, importantly, preserve teeth with vital pulp, other methods can be used such as stepwise excavation, partial caries removal and cavity restoration during the same visit, and no dentinal caries removal combined with the use of steel crowns, particularly in multi-rooted deciduous teeth [2-8].

The aim of the paper is to compare the efficacy of five deep caries treatment methods based on the literature. The work focuses on methods which are minimally invasive for hard dental tissues and ensure maximum protection of vital dental pulp. 


\section{CONVENTIONAL TREATMENT}

The treatment of deep carious cavities often involves complete removal of carious lesions and demineralized dentine during a single visit. This is the conventional approach to caries treatment. Such procedures are often associated with iatrogenic or caries-induced pulp exposure, which is particularly likely in the case of primary and young permanent teeth. The technique is also associated with substantial tissue loss, long duration of the procedure and the need for anaesthesia $[6,9,10]$.

A four-year randomised study comparing glass ionomer cement with a composite showed a similar therapeutic effect after conventional treatment. Equia Fil and Gradia Direct Posterior were used to fill 140 Black class I and II cavities. The shape of restoration, the presence of secondary caries, postoperative sensitivity and dental filling colour were assessed [11].

Leksell et al. [10] observed treatment failure involving pulp exposure in $40 \%$ of cases for complete caries removal compared to $17.5 \%$ for stepwise excavation. The study focused on first permanent molars. The use of direct pulp capping or partial pulpotomy in such cases was successful in $31.8 \%$ and $34.5 \%$ of patients, respectively, after one year from treatment [12]. Pulp necrosis developed in $44.5 \%$ of cases within 5 years and in $79.7 \%$ of teeth within 10 years after direct pulp capping [13]. In such cases, endodontic treatment or tooth extraction is necessary. Based on a meta-analysis of 10 studies in 1257 participants, there was a significantly reduced risk of pulpal complications after incomplete versus complete excavation [14].

\section{INDIRECT PULP TREATMENT}

This well-known approach, also referred to as indirect pulp capping, is based on the theory of infected and affected dentin. The infected tissue consists of a soft layer of dentin adjacent to the cavity and is composed of damaged collagen fibres that cannot be remineralised. The deeper affected layer contains uninfected intact collagen fibres and can be remineralised. The operator leaves a thin layer of demineralised dentin with significantly fewer bacteria to avoid pulp exposure. In the next step, the dentin is covered with a biocompatible liner such as zinc oxide, calcium hydroxide or, recently, glass ionomer cement (GIC) to prevent the dentin-pulp complex. This is followed by restoration [3, 15-17]. Indirect pulp treatment (IPT) and pulpotomy are both recommended by the American Academy of Pediatric Dentistry for the treatment of deep caries in primary teeth [4].

This procedure obviously requires an experienced operator as it is difficult to decide how much dentin should be removed. Several methods of varying efficacy have been developed to distinguish between infected and affected tissue. When applying caries disclosing dyes, the sound dentin is stained as well, leading to misinterpretation. Some authors make use of the fact that only infected tissue is painless, while demineralized tissue is tender to invasive treatment. However, some patients require anaesthesia [6].

Rosenberg et al. [3] treated deep carious lesions in primary molars with the IPT technique using a resin-modified glass-ionomer liner. Liner application was preceded by cavity disinfection with $2 \%$ chlorhexidine gluconate. Finally, the cavities were filled with composite or the teeth were restored with stainless steel crowns. After clinical, radiographic and photographic examination, the success rates were as follows: $100 \%$ at 3 months, $98 \%$ at 6 months and $97 \%$ of teeth at 12 -month follow-up. Interradicular pathology was considered a therapeutic failure [3]. The same method with the use of GIC and calcium hydroxide cement as an indirect dentin liner was assessed in primary teeth. After a minimum observation period of four years, the therapy was considered satisfactory, with success rates of $93 \%$ and $89 \%$, respectively [17]. Some authors have been trying to prevent the dentin-pulp complex by means of an adhesive resin system appliance. They noted a 93\% success rate vs. $80 \%$ for teeth treated with calcium hydroxide liner. The observation was made at 2- to 5-year follow-up in relation to the time when the first part of the study was finished. The first part ended after a 2-year follow-up period, when some of the children failed to report for a follow-up, and thus did not participate in the second part of the study. Histological evaluation of exfoliated teeth treated with the adhesive method showed sound pulp with the features corresponding to the development stage [16].

Opal et al. [18] classified stepwise excavation and partial/incomplete caries removal as the IPT approach. In the present study, these two methods are considered to be based on a different treatment philosophy. The dentin remaining after partial caries removal is more likely to become demineralised and infected.

\section{STEPWISE EXCAVATION}

During the first visit, carious dentine is completely removed from the walls of the cavity. Disintegrated dentine is also removed, with carious lesions being left at the bottom of the cavity. Subsequently, the cavity is rinsed with distilled water, dried with sterile absorbent points and filled with a temporary material, i.e. zinc oxide with eugenol or GIC, for 1-6 months. Some researchers recommend applying calcium hydroxide base material over the demineralised dentin. The sealing of the initially prepared cavity deprives bacteria of the substrate they need to live. This reduces the number and diversity of bacteria, changes $\mathrm{pH}$ and, as a result, stops caries progression. Due to reduced harmful stimulation of the pulp, tertiary and sclerotic dentine is 
formed. Properly formed dentine is a decisive factor for the protection against pulp exposure. Also, the closure of dentinal tubules in the form of sclerotic dentin prevents caries progression. The newly formed tertiary dentine can be observed non-invasively on radiographs as a higher radiopacity area $[9,10,12,19]$. This is evidence for the ability of the pulp to defend itself using biological mechanisms.

At the second visit after 1-6 months, the cavity is reopened, completely excavated and filled with a permanent restoration. Some researchers reported no progression of caries even after a 10-year period of observation $[9,10,12,19]$.

Following partial removal of carious dentine, a statistically significant decrease of anaerobic bacteria and Streptococcus mutans is observed compared to complete caries removal during a single visit [20]. A recent study demonstrated that treatment success after use of this method in permanent teeth was achieved in $74.1 \%$ of cases compared to $62.4 \%$ in the group of patients treated with direct complete excavation after 12 months of follow-up. Pulp exposure was identified in $17.5 \%$ of teeth treated with stepwise excavation and $28.9 \%$ of teeth after complete caries removal. The difference was significant [12]. In the next research, 1-visit indirect pulp therapy (IPT), 2-visit IPT and complete caries removal were performed in primary and young permanent molars. Calcium hydroxide was used for indirect pulp capping during the first or the second follow-up after partial caries removal at the first visit. Therapeutic success was estimated at 3-month intervals up to 12 months after treatment. Pulp exposure was found in $6 \%$ of teeth treated with the 1 -visit method, in $8 \%$ in 2 -visit therapy and in $22 \%$ of completely cleaned teeth. The remaining teeth were monitored with success rates of $100 \%, 98 \%$ and $95 \%$ respectively, for these three treatment methods [6].

The concept of stepwise excavation is helpful in non-cooperative and disabled children with severe rampant caries. It allows reduction of the number of bacteria in the oral cavity in a short treatment time. Following partial caries removal, the interim therapeutic restoration (ITR) is placed in all of the carious teeth. In the next step, pulpal status is determined and final cleaning is recommended due to the possible patient cooperation. After IPT or pulpotomy, a permanent filling is applied. The retrospective study assessed two different treatment methods, vital pulp therapy (VPT) vs. ITR. The first group of primary teeth was treated by total caries removal followed by VPT-IPT or a pulpotomy procedure. In the second group, ITR was performed first and, after an appropriate mean follow-up time of 3.2 months, IPT or pulpotomy was performed. For the VPT group the following criteria for failure were applied: postoperative pain, abnormal mobility, presence of a sinus tract, gingival swelling and periapical radiolucency on radiograph. For the ITR group, treatment failure was ob- served when the symptoms of irreversible pulpitis were diagnosed. Success rates were $94 \%$ for ITR versus $78 \%$ for VPT [4].

\section{PARTIAL/INCOMPLETE CARIES REMOVAL}

Another method involves partial removal of carious dentine and cavity restoration during the same visit. Lesions are completely removed from the walls and only disintegrated dentine is removed from the bottom of the cavity. The cavity is rinsed using distilled water and dried with sterile cotton wool balls. The cavity is then filled using the closed sandwich technique or GIC only. The primary aim of such cavity management is to preserve vital pulp by reducing the risk of iatrogenic complications during caries removal because pulp exposure was more common during the second visit of stepwise excavation [14]. This approach is also based on the reducing effect of the lack of available substrates on bacterial metabolism, which was proved experimentally. Maltz et al. [9] revealed increased dentin hardness and a decreased number of bacteria after a 7-month experimental period in most cases of partial caries removal, which is evidence for arrested caries.

In this method, it is important to properly diagnose the condition of the pulp as it is possible to use the pulpal defensive potential provided that the pulp is healthy or even reversibly inflamed. Correct diagnosis can only be made based on clinical manifestations such as positive reaction to pulp vitality tests, the absence of pain on percussion, no history of spontaneous pain and the absence of periapical lesions on the radiograph. The method is presented by the authors in photographs (Figures 1 and 2).

A comparative review of studies on partial vs. complete caries removal reported a $77 \%$ decrease in the risk of pulp exposure for partial caries removal [21]. Randomised studies conducted by Maltz et al. [22] compared partial caries removal with stepwise excavation. The permanent molars included in the treatment had deep carious lesions with one-half or more of dentine loss seen on radiographs. The study included 299 teeth of individuals aged 6-53 years, regardless of gender or the number of restored surfaces. After 18 months, the treatment success rate for 212 cases was $99 \%$ and $86 \%$ after partial caries removal and stepwise excavation, respectively. A complication in the form of irreversible pulpitis occurred in one patient after partial caries removal, while stepwise excavation involved eight cases of irreversible pulpitis, four cases of pulp necrosis and one case of osteitis. Based on these results the researchers concluded that the remaining caries left at the cavity bottom does not affect pulp vitality. Therefore, it is not necessary to reopen the cavity to complete its excavation [22]. Similar results were presented in comparative studies on the two methods after a 3-year follow-up period. 

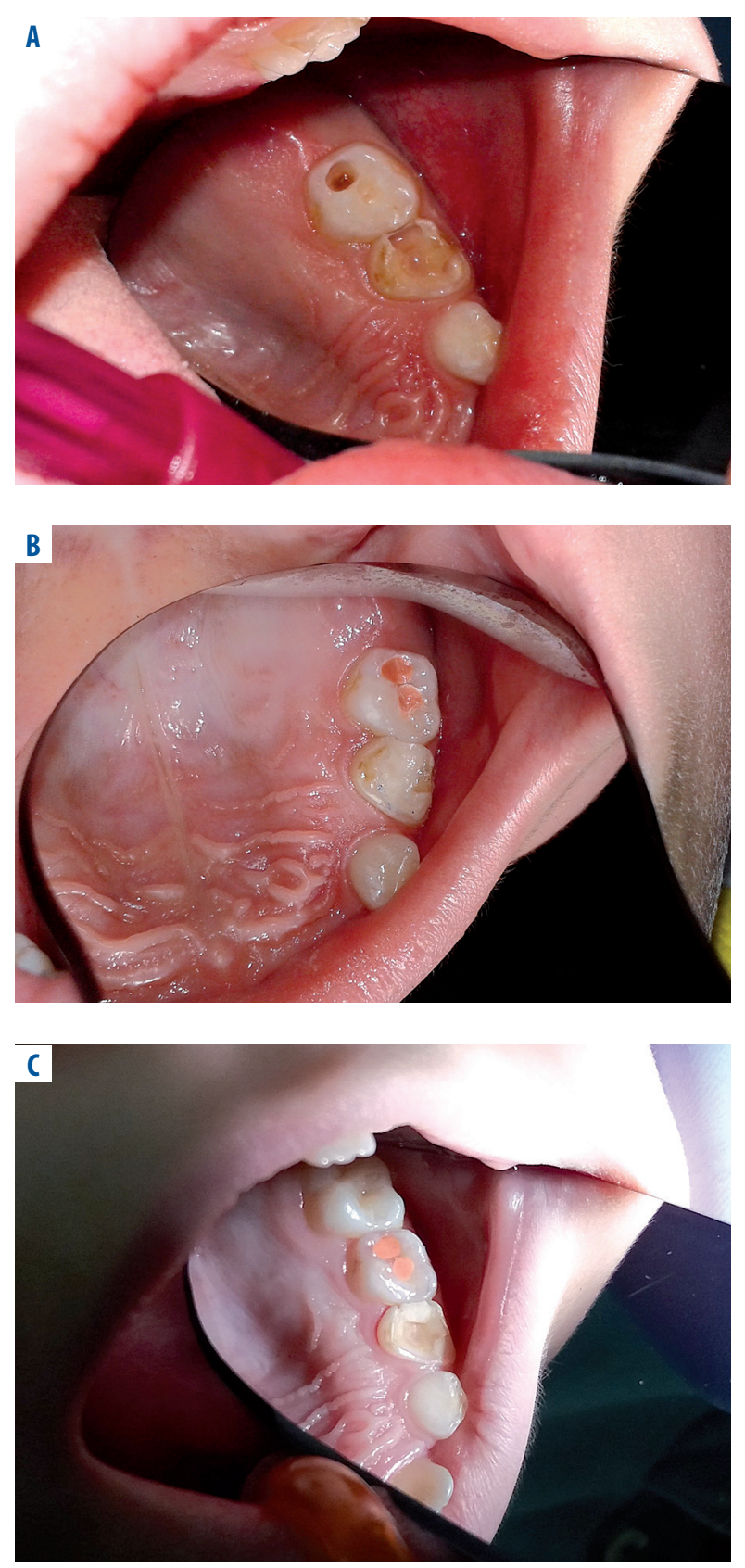

FIG. 1. A) Deep caries management of primary maxillary left second molar with incomplete 1-visit caries removal - after debridement of disintegrated dentin. B) Deep caries management of primary maxillary left second molar with incomplete 1-visit caries removal - cavity filled with Fuji Triage (GC, Japan). C) Deep caries management of primary maxillary left second molar with incomplete 1-visit caries removal - follow-up image after 2 years of observation

The study included 299 permanent molars with deep carious lesions. The teeth were positive to ethyl chloride, were negative to percussion, there was no history of spontaneous pain and there were no radiographic abnormalities. Teeth with lost cusps or subgingival caries
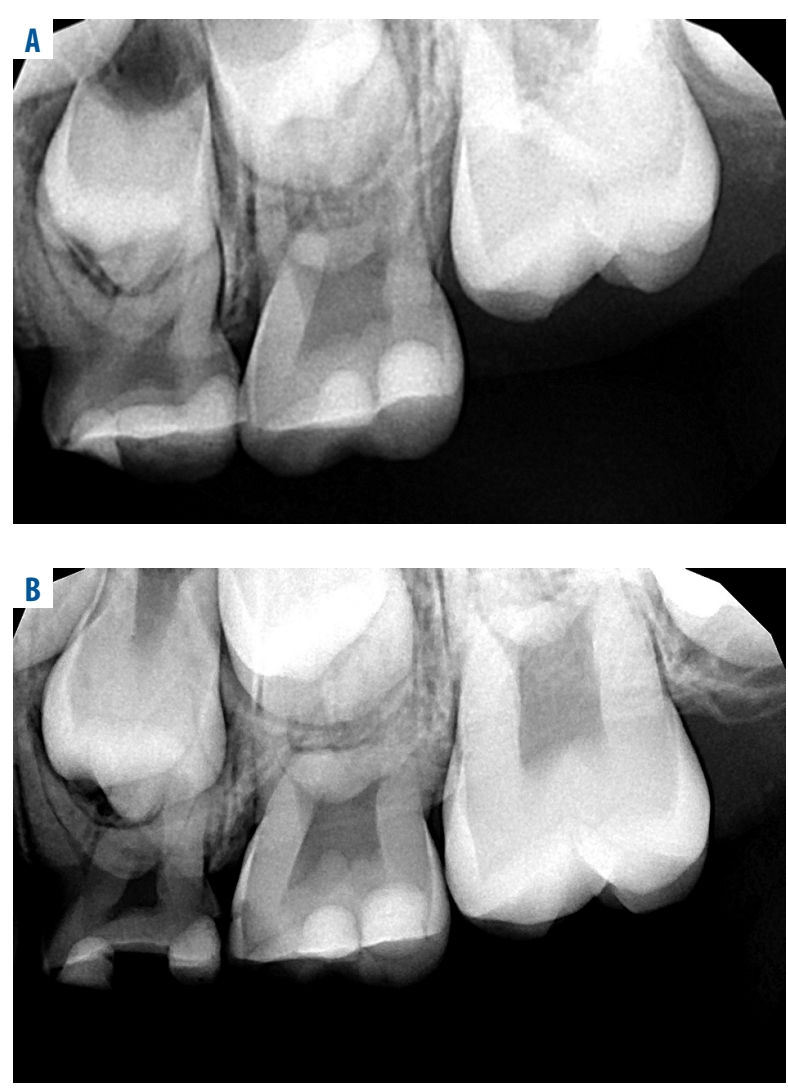

FIG. 2. A) Radiograph after treatment and cavity restoration in the tooth shown in Figure $1-$ a thin layer of demineralized dentin under the glass ionomer cement filling is seen. B) Two-year follow-up radiograph no progression of caries is noted and the newly formed secondary dentin is present

were not taken into account. Partial caries removal was performed in 152 teeth. After the administration of anaesthesia and the placement of a dental dam the cavity was accessed using a diamond bur. Subsequently, carious dentine was removed from the cavity walls using a slow-speed drill. Caries was partially removed from the bottom using hand excavators. The cavity was rinsed with distilled water, dried and filled using the closed sandwich technique - GIC with amalgam or composite. Stepwise excavation of caries was performed in 147 teeth. After partial removal of caries, calcium hydroxide was applied to the teeth. The cavity was temporarily filled with zinc oxide with eugenol for 60 to 120 days. After this period, the remaining carious dentine was removed and the cavities were permanently restored. After three years, there were 213 teeth left in the study. The treatment was considered successful if the teeth positively reacted to cold, there was no spontaneous pain, the teeth were negative to percussion and there were no radiographic abnormalities. Success rates were $91 \%$ for partial caries removal and $69 \%$ for stepwise excavation. This study also confirmed that it is not necessary 
to reopen the cavity in order to remove the remaining caries [23].

Partial caries removal is associated with the biomimetic approach to dental treatment. It is a new method which replaces "prepare and restore" with the "seal and treat" idea. This method takes advantage of the defensive abilities of the pulp and the mineralisation effect of glass ionomer materials. Active caries constitutes an imbalance between demineralization and remineralisation with the ultimate loss of minerals such as calcium and phosphates. The goal of biomimetic dentistry is to restore the disturbed balance by supplying the lost minerals to the cavity using a glass-ionomer filling. Before the filling is applied, the partially excavated cavity should be disinfected with $1 \%$ sodium hypochlorite, filled with glass ionomer material and light-cured in order to achieve improved properties of the material and accelerate bonding owing to the light's heat. After light curing, there is no need to apply a liquid coating in order to protect the glass ionomer filling.

Atraumatic restorative treatment (ART) is one of the current treatment options for non-cooperative patients or practices without appropriate dental equipment. Partial caries removal using only hand instruments is performed according to the concept of minimal intervention. This mostly painless method allows anxiety and treatment duration to be reduced. GIC is the material of choice for this technique. Its properties such as biocompatibility, good sealing to the enamel and dentin, as well as fluoride release and uptake, are of the utmost importance [1, 2, 7, 24-26]. The efficacy of ART was established in 6-7-year-old children with class I and II cavities of primary molars. Success rates after a 12-month follow-up were $50.6 \%$ and $15.2 \%$ for class I and II, respectively, and were relatively low in comparison with the studies cited in the literature. The main reason for failure was total or partial loss of restoration [1]. It is difficult to evaluate the technique when class II cavities are included in the study. A high number of class II restorations are often lost in primary dentition. Insufficient caries removal may not be the only cause of failure [1,26-28]. In another one-year follow-up study, a comparable analysis of 2 different glass ionomer cements placed in primary molars was conducted. Success rates for materials for class I restorations were $97.4 \%$ and $94.9 \%$. Survival rates for class II restorations were $95.1 \%$ and $88.5 \%$. Also, no caries was detected as all of the intact pits and fissures had been sealed with glass ionomer [7].

One- or two-step partial caries removal techniques are primarily intended for developing teeth due to the greater potential of the pulp to produce reparative dentin. The older the patient, the more fibrous pulp there is, as well as decreased blood supply with reduced regeneration potential of the pulp [18]. Furthermore, an assessment of the degree of excavation is a major problem. A misinterpretation may lead to incorrect diagnosis [14].

\section{NO DENTINAL CARIES REMOVAL/HALL TECHNIQUE}

The Hall technique is the method of managing caries without using rotary instruments and local anaesthesia. It is recommended for primary molars where caries involves two or more surfaces. Decay is arrested under preformed metal crowns without any caries removal. The metal crown is filled with glass ionomer luting cement. If the cavity is large, some glass ionomer can be placed at the base of the cavity before cementing the crown $[29,30]$.

Comparative research on conventional treatment versus no caries removal in asymptomatic deciduous molars was conducted. Steel crowns were used in teeth without any caries removal. In this study, improved pulpal status and restoration durability were observed in the study group after a minimum of 23 months of follow-up. It was also noted that $77 \%$ of children preferred to have steel crowns fitted without caries removal [30]. Clinically and radiographically successful results were also obtained in another study with the same technique used in primary molars. The clinical success rates of $98.9 \%$ and $97.4 \%$ were noted after a mean follow-up time of 9.9 and 20.1 months, respectively [29]. Another study concerned permanent teeth with class I cavities, which were restored using a composite material. This study also did not find any differences between the study group and the control group in terms of the occurrence of irreversible pulpitis or filling loss after a 2-year follow-up [31].

\section{CONCLUSIONS}

The present study suggests the need to limit complete preparation of the cavity in the treatment of deep caries. Such management is associated with the risk of pulp exposure, involves substantial hard dental tissue loss and is time-consuming, which additionally increases dental anxiety.

Stepwise excavation seems to have more drawbacks than advantages. Indeed, temporary cavity restoration aims to reduce the number of bacteria and turn an active carious lesion into an inactive lesion. An inactive cavity is dry, hard and darker in colour. However, during further caries removal at the second visit pulp injury often occurs. Other disadvantages of this method include the possible loss of the temporary filling, higher treatment costs and the risk of the patient's failure to report for another visit. It therefore seems reasonable to use less invasive techniques.

Partial caries removal spares hard dental tissues and reduces the risk of pulp injury. The procedure is shorter and less painful. Protecting hard tissues and the pulp of the tooth from injury prolongs its vitality. The development of a permanent tooth with an open apex is 
undisturbed. Uncertain and costly endodontic treatment, which is often impossible to perform, particularly in children (lack of cooperation, long-lasting procedure, difficult access due to insufficient opening of the mouth, multi-rooted teeth with uncompleted development), can be avoided. Finally, tooth extraction can also be avoided, thus eliminating the risk of masticatory system abnormalities both in children and adults. Shorter treatment duration, and reduced pain and costs, render the procedures more pleasant, which contributes to patient satisfaction.

No dentinal caries removal combined with the use of steel crowns does not affect the risk of irreversible tooth inflammation. Steel crowns are more durable than ordinary fillings and children prefer this method to traditional caries removal. However, the method is generally recommended only for non-cooperative patients.

\section{CONFLICT OF INTEREST}

The authors declare no potential conflicts of interest with respect to the research, authorship, and/or publication of this article.

\section{References}

1. da Franca C, Colares V, van Amerongen E. Two-year evaluation of the atraumatic restorative treatment approach in primary molars class I and II restorations. Int J Paediatr Dent 2011; 21: 249253.

2. Wadenya RO, Yego C, Mante FK. Marginal microleakage of alternative restorative treatment and conventional glass ionomer restorations in extracted primary molars. J Dent Child 2010; 77: 32-35.

3. Rosenberg L, Atar M, Daronch M, et al. Prospective study of indirect pulp treatment in primary molars using resin-modified glass ionomer and $2 \%$ chlorhexidine gluconate: a 12 -month follow-up. Pediatr Dent 2013; 35: 13-17.

4. Coll JA, Campbell A, Chalmers NI. Effects of glass ionomer temporary restorations on pulpal diagnosis and treatment outcomes in primary molars. Pediatr Dent 2013; 35: 416-421.

5. Scottish dental clinical effectiveness programme prevention and management of dental caries in children. Dental clinical guidance. Part III. J Stoma 2012; 65: 440-464.

6. Orhan AI, Oz FT, Orhan K. Pulp exposure occurrence and outcomes after 1- or 2-visit indirect pulp therapy vs complete caries removal in primary and permanent molars. Pediatr Dent 2010 32: 347-355.

7. Gurunathan D, Tandon S. A clinical evaluation of two glass ionomer cements in primary molars using atraumatic restorative treatment technique in India: 1 year follow up. Int J Paediatr Dent 2010; 20: 410-418.

8. Pawlaczyk-Kamieńska T. Nowe propozycje leczenia próchnicy zębów mlecznych - na podstawie piśmiennictwa. Czas Stomatol 2010; 63: 638-644

9. Maltz M, Oliveira EF, Fontanell V, Bianchi R. A clinical, microbiologic, and radiographic study of deep caries lesions after incomplete caries removal. Quintessence Int 2002; 33: 151-159.

10. Leksell E, Ridell K, Cvek M, Mejare I. Pulp exposure after stepwise versus complete excavation of deep carious lesions in young posterior permanent teeth. Endod Dent Traumatol 1996; 12: 192-196.

11. Gurgan S, Kutuk ZB, Ergin E, et al. Four-year randomized clinical trial to evaluate the clinical performance of a glass ionomer restorative system. Oper Dent 2015; 40: 134-143.
12. Bjorndal L, Reit C, Bruun G, et al. Treatment of deep caries lesions in adults: randomized clinical trials comparing stepwise vs. direct complete excavation, and direct pulp capping vs. partial pulpotomy. Eur J Oral Sci 2010; 118: 290-297.

13. Barthel CR, Rosenkranz B, Leuenberg A, Roulet JF. Pulp capping of carious exposures: treatment outcome after 5 and 10 years: a retrospective study. J Endod 2000; 26: 525-528.

14. Schwendicke F, Dorfer CE, Paris S. Incomplete caries removal: a systematic review and meta-analysis. J Dent Res 2013; 92: 306-314.

15. Casagrande L, Bento LW, Dalpian DM, et al. Indirect pulp treatment in primary teeth: 4-year results. Am J Dent 2010; 23: 34-38.

16. Casagrande L, Falster CA, Hipolito VD, et al. Effect of adhesive restorations over incomplete dentin caries removal: 5-year follow-up study in primary teeth. J Dent Child 2009; 76: 117-122.

17. Marchi JJ, de Araujo FB, Froner AM, et al. Indirect pulp capping in the primary dentition: a 4 year follow-up study. J Clin Pediatr Dent 2006; 31: 68-71.

18. Opal S, Garg S, Dhinda A, Taluja T. Minimally invasive clinical approach in indirect pulp therapy and healing of deep carious lesions. J Clin Pediatr Dent 2014; 38: 185-192.

19. Oliveira EF, Carminatti G, Fontanella V, Maltz M. The monitoring of deep caries lesions after inclomplete dentine caries removal: results after 14-18 months. Clin Oral Invest 2006; 10: 134-139.

20. Bjorndal L, Larsen T, Thylstrup A. A clinical and microbiological study of deep carious lesions during stepwise excavation using long treatment intervals. Caries Res 1997; 31: 411-417.

21. Ricketts D, Lamont T, Innes NPT, et al. Operative caries management in adults and children (Review). Cochrane Database Syst Rev 2013; 3: 1-54.

22. Maltz M, Jardim JJ, Mestrinho HD, et al. Partial removal of carious dentine: a multicenter randomized controlled trial and 18-month follow-up results. Caries Res 2013; 47: 103-109.

23. Maltz M, Garcia R, Jardim JJ, et al. Randomized trial of partial vs. stepwise caries removal: 3-year follow-up. J Dent Res 2012; 91: 10261031.

24. Lenzi TL, Bonifacio CC, Bonecker M, et al. Flowable glass ionomer cement layer bonding to sound and carious primary dentin. J Dent Child 2013; 80: 20-24.

25. Marczuk-Kolada G, Łuczaj-Cepowicz E. Clinical evaluation of the effectiveness of atraumatic restorative treatment of caries in deciduous teeth - a three-year study. J Stoma 2011; 64: 145-160.

26. Kemoli AM, van Amerongen WE, Opinya GN. Short communication: Influence of different isolation methods on the survival of proximal ART restorations in primary molars after two years. Eur Arch Paediatr Dent 2010; 11: 136-139.

27. de Amorim RG, Leal SC, Frencken JE. Survival of atraumatic restorative treatment (ART) sealants and restorations: a meta-analysis. Clin Oral Invest 2012; 16: 429-441.

28. dos Santos MPA, Luiz RR, Maia LC. Randomized trial of resinbased restorations in class I and II beveled preparations in primary molars: 48-month results. J Dent 2010; 38: 451-459.

29. Clark W, Geneser M, Owais A, et al. Success rates of Hall technique crowns in primary molars: a retrospective pilot study. Gen Dent 2017; 65: 32-35.

30. Innes NP, Evans DJP, Stirrups DR. The Hall Technique; a randomized controlled clinical trial of a novel method of managing carious primary molars in general dental practice: acceptability of the technique and outcomes at 23 months. BMC Oral Health 2007; 7: 1-21.

31. Mertz-Fairhurst EJ, Call-Smith KM, Shuster GS, et al. Clinical performance of sealed composite restorations placed over caries compared with sealed and unsealed amalgam restorations. J Am Dent Assoc 1987; 115: 689-694. 